Journal of Germanic Linguistics 14.2 (2002):137-175.

\title{
A Morphological Analysis of Definite Nouns in Danish*
}

\author{
Jorge Hankamer and Line Mikkelsen \\ University of California, Santa Cruz
}

\begin{abstract}
We argue that the distribution of definiteness marking in Scandinavian DPs is best accounted for by a lexical rule converting Ns to Ds, and not by syntactic head movement. The proposed lexical rule, together with the assumption that lexical expressions can block equivalent phrasal expressions, is shown to account for the core facts about definiteness marking distribution in Danish, and is extended to Swedish and Norwegian. In addition, some previously mysterious facts about definiteness marking in DPs containing relative clauses are explained.
\end{abstract}

\section{Introduction.}

In the Scandinavian languages, including Danish, Faroese, Icelandic, Norwegian, and Swedish, there are two ways definiteness can be expressed in a noun phrase: by a suffix on the noun or by a prenominal lexical determiner. The distribution of the two definiteness markers differs among the languages and among dialects. In this paper we focus on definiteness marking in standard Danish. ${ }^{1}$ The two ways of marking definiteness are illustrated in 1: 1a contains the definite suffix, and 1b a

\footnotetext{
* Earlier versions of this paper were presented at UCSC, GLAC 7 in Banff, Universitetet i Troms $\varnothing$, Háskóli Íslands, Universität Konstanz, University of Oxford, University College London, UC San Diego, and in a morphology seminar in the fall term of 2001 at SOAS. We would like to thank audiences at these venues, as well as Judith Aissen, Ash Asudeh, Kersti Börjars, Sandy Chung, Lars-Olof Delsing, Donka Farkas, Anya Hogoboom, Chris Potts, Elizabeth Ritter, Bodil Kappel Schmidt, Peter Svenonius, Arnold Zwicky, and the two anonymous JGL reviewers for comments, help, and discussion. A preliminary version of the analysis for Danish has been published as Hankamer and Mikkelsen 2001. The work of the second author was supported by a grant from the Danish Humanities Research Council.

${ }^{1}$ The only dialect of Danish that differs from the standard one in this respect is West Jutlandic, which has no definite suffix (Hansen 1927:130-150).
}

(c) Society for Germanic Linguistics 
prenominal definite article. We refer to forms like hesten in $1 \mathrm{a}$ as DEFINITE NOUNS. ${ }^{2}$

(1) a. hest-en

horse-DEF

'the horse'

b. den røde hest

DEF red horse

'the red horse'

Delsing (1993) argues that both structures involve a definiteness marker base-generated in $\mathrm{D}$, and that $1 \mathrm{a}$ is derived by head movement of $\mathrm{N}$ to $\mathrm{D}$. Delsing's analysis falls within a family of recent proposals that there is head movement of $\mathrm{N}$ to $\mathrm{D}$ in various types of noun phrases in various languages, including Ritter 1988:914-921 for Hebrew, Mohammad 1988:249-254 for Arabic, Longobardi 1994 for Italian, and Duffield 1995:282-322 for Celtic. In a recent paper in the framework of Distributed Morphology, Embick and Noyer (2001) adopt the essence of Delsing's analysis as the syntactic underpinning for their treatment of definiteness in Swedish and Danish.

In this paper we argue against a head-movement analysis of definiteness marking in Danish, and present an alternative analysis where hesten is a determiner derived in the lexicon by a morphological rule. There are at least three advantages to our analysis. First, it accounts for the distribution of the two definiteness markers, while maintaining an empirically and theoretically well-motivated internal structure for Danish DPs. Second, our morphological approach is compatible with the existence of morphologically defined gaps in the distribution of the definite suffix. Third, the analysis resolves a long-standing puzzle about definiteness marking in DPs containing relative clauses.

\footnotetext{
${ }^{2}$ Both definiteness markers show number and gender in Danish, agreeing with the head noun (see Mikkelsen 1998b for data and discussion). Since these distinctions are not relevant for the issues of definiteness marking we discuss in this paper, we illustrate with singular common gender DPs where possible. In a singular common gender DP, the definite suffix is realized as -en and the prenominal definite article as den. Both are glossed DEF. Other glosses used are: COM for common gender, DEM for demonstrative, NEU for neuter gender, PL for plural, POSS for possessive, PRP for present participle, and SG for singular.
} 
The paper is organized as follows. In section 2 we present Delsing's head-movement analysis and discuss a number of theoretical and empirical problems with it. In section 3 we present our analysis and show how it accounts for the distribution of the two definiteness markers in Danish, including facts not accounted for by the head-movement analysis. In section 4 we discuss relative clauses in more detail, showing how our proposal interacts with the analysis of Danish relative clauses, in particular their adjunction site and interpretation. In section 5 we discuss how the analysis could be extended to account for definiteness marking in Swedish and Norwegian. Finally, in section 6 we summarize and discuss some general issues arising from the analysis proposed here for Scandinavian languages.

\section{The Head-Movement Analysis.}

Partly following Abney (1987), Delsing (1993) assumes a DP structure where D takes either an NP, AP or Deg(ree)P complement. Definite and indefinite determiners are generated in $\mathrm{D}$, and when a definite $\mathrm{D}$ takes an $\mathrm{NP}$ complement $\mathrm{N}$ moves to $\mathrm{D}$, and $\mathrm{D}$ is realized as a suffix on $\mathrm{N}$ (Delsing 1993:74, ex. 14):

(2)

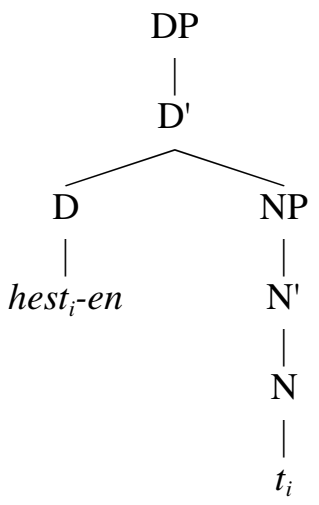

The definite suffix does not cooccur with attributive adjectives, as shown in 3 .

(3) a. *hest-en røde horse-DEF red

b. *røde hest-en red horse-DEF 
Delsing proposes that this follows from the adjective blocking head movement of $\mathrm{N}$ to D (Delsing 1993:81, ex. 28):

(4)

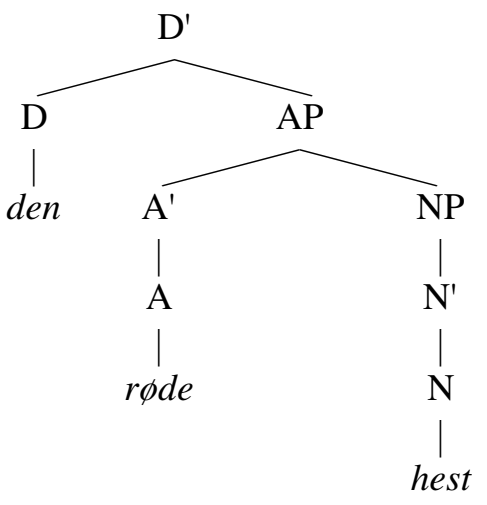

The adjective in $\mathrm{A}$ intervenes (in terms of m-command) between $\mathrm{N}$ and $\mathrm{D}$, blocking $\mathrm{N}$ to $\mathrm{D}$ movement. Being unable to move, the noun appears in situ $(\mathrm{N})$, and definiteness marking is realized as the lexical definite article den in $\mathrm{D}$.

We discuss first some theoretical problems with the head-movement analysis (section 2.1) and then some empirical problems (sections 2.2 and 2.3).

\subsection{Theoretical Objections.}

In 4, which is the structure proposed by Delsing (1993) for DPs containing an adjective, the AP is the complement of D, and NP is analyzed as a specifier of AP. While we agree that D is the head of the entire projection in 4, and that A heads an AP, we do not agree that AP is the complement of D. Instead we maintain a more traditional analysis, where AP is adjoined to NP, and NP is the complement of D (see section 3.2). Evidence that $\mathrm{N}$, and not $\mathrm{A}$, heads the complement of $\mathrm{D}$ in Scandinavian is given by Svenonius (1992b). Based on the criteria for headedness proposed in Zwicky 1985, Svenonius (1992b:109-117) argues that $\mathrm{A}$ is not the head of the complement of $\mathrm{D}$, since $\mathrm{A}$ fails most of the criteria for being a head of this domain: it is not obligatory, it is not unique, and it does not control features on the NP it modifies. In contrast, $\mathrm{N}$ passes all of these criteria, and we conclude with Svenonius (1992b) that $\mathrm{N}$ rather than A heads the complement of $\mathrm{D}$.

The analysis proposed by Delsing requires determiners to take at least three different kinds of complements: NP, AP, and DegP. The latter case is instantiated when A is modified by a word like very, which is 
assumed to head a Degree Phrase, as proposed in Abney 1987:189-204. This multiplication of subcategorization possibilities seems empirically unmotivated in Danish, since there are no determiners allowing only a subset of these possibilities. All determiners can appear with no adjective (taking an NP complement), an unmodified adjective (taking an AP complement), or a modified adjective (taking a DegP complement). The problem with Delsing's analysis is thus that it shifts the optionality of adjectives and their modifiers to the subcategorization of the determiner. We assume a more traditional analysis where AP is left-adjoined to NP. This analysis locates the optionality where it should be located-in the adjunct status of adjectives - and the determiner simply takes an NP argument. Note also that the right-hand specifier position that Delsing proposes for the NP goes against the general head-directionality of Danish: complements are uniformly to the right, and specifiers uniformly to the left. ${ }^{3}$ This particular feature of the analysis (NP as a right-hand specifier of AP) is not, in fact, crucial to the overall account of the distribution of definiteness marking, so it is important to note that our other objections, both empirical and theoretical, hold equally against a head-raising analysis assuming a structure like that proposed by Abney (1987:213, ex. 395a) in which NP is the complement of A, rather than the specifier of AP. ${ }^{4}$

The main theoretical problem with the head-raising analysis resides in its most crucial assumption about the syntactic structure: namely that in a structure involving an adjective, $\mathrm{A}$ is the head of the complement of D. This assumption is crucial because an A in any other structural position (adjunct or specifier) would not, under either the Head Movement Constraint of Travis (1984:131) or the Relativized Minimality Constraint of Rizzi (1990), block head raising of N to D. But this raises

\footnotetext{
${ }^{3}$ Specifier-left order is observed also in small clauses, where the subject uniformly precedes the predicate:

(i) Jeg gjorde [ Peter gal $]$.

I made Peter mad

(ii) Jeg malede [ port-en blå ].

I painted gate-DEF blue

${ }^{4}$ In particular, they hold against the syntactic part of the analysis in Embick and Noyer 2001:568, 582, which assumes a head-raising analysis and an Abneystyle structure.
} 
an embarrassing question: if $\mathrm{A}$ is the head of the complement of D in DA-N constructions, which it must be in order to block N-to-D raising, what prevents A-to-D raising in such structures? As shown in 5, the definiteness marker cannot appear on adjectives, even when there is no overt noun present. ${ }^{5}$
a. *rød-en hest red-DEF horse
b. *rød-en
red-DEF

Note that in the structure in 4, D and $\mathrm{A}$ are in the exact configuration that $\mathrm{D}$ and $\mathrm{N}$ are in in the structure in 2 . Since the head-raising analysis assumes that $\mathrm{N}$ moves to $\mathrm{D}$ in 2 , we would expect $\mathrm{A}$ to be able to move to $\mathrm{D}$ in 4 . The same question (why A does not move to $\mathrm{D}$ ) arises for Longobardi's (1994) analysis of N-to-D movement of proper names in Western Romance. Longobardi is assuming a more standard DP analysis, where NP is the complement of D, and APs are in Spec NP, and suggests that A-to-D movement is ruled out by the Head Movement Constraint, since "A is not the head of the complement of D" (1994:644). This explanation is not available to Delsing, because in his analysis A must be the head of the complement of $\mathrm{D}$. Delsing notes this problem (1993:91-92) and suggests that syntactic categories like $\mathrm{N}$ and $\mathrm{A}$ have a binary valued feature [ \pm head movement], and that the value of this feature is subject to parametric variation. ${ }^{6}$ In the absence of further

${ }^{5}$ There are grammatical noun phrases (occurring only in certain fixed idiomatic expressions) where an attributive adjective carries a suffix -en, but this is a remnant of an old accusative suffix, unrelated to the definite suffix (Diderichsen 1946:110-111):

(i) sort-en muld black-ACC soil

(ii) blid-en bør soft-ACC wind

We thank Bodil Kappel Schmidt for bringing these facts to our attention.

${ }^{6}$ Embick and Noyer (2001:582) do, in effect, the same thing. They say “(62) N moves to D if possible." and “... (62) is restricted to N ...", in effect stipulating that A cannot move to D. Why this should be so, if A is the head of the complement of $\mathrm{D}$, remains mysterious. 
evidence for the head movement feature, this seems to be nothing more than a restatement of the facts.

In addition to these theoretical objections, the head-movement approach faces some empirical challenges. We first show that definiteness marking in DPs containing a relative clause is not adequately accounted for under the head-movement analysis (section 2.2). We then show that there are at least two instances where definiteness marking is sensitive to morphology (section 2.3). This is unexpected under the head-movement analysis where the distribution of definiteness is governed by syntactic movement, which is sensitive to syntactic structure, but not word-internal morphology. ${ }^{7}$

\subsection{Definiteness Marking and Relative Clauses.}

In the absence of prenominal modifiers, prenominal definiteness marking is impossible (the string in 7 is grammatical as a demonstrative DP when den is stressed, as shown in 8):

(6) hest-en

horse-DEF

'the horse'

(7) *den hest

DEF horse

(8) dén hest

DEM horse

'that horse'

To account for the fact that 7 is not a licit use of the prenominal definite article under the head-movement analysis, it must be assumed that N-to$\mathrm{D}$ movement is obligatory where possible ${ }^{8} 7$ is then ungrammatical

\footnotetext{
${ }^{7}$ At least under the StRONG LeXICALIST HyPOTHESIS (Scalise 1984:101ff.), which states that syntax cannot refer to or modify the internal structure of words (LaPointe 1980:222), see also Pullum and Zwicky 1991:389-390. In the framework of Distributed Morphology (Halle and Marantz 1993) morphological elements are present and active in syntax and vocabulary insertion happens postsyntactically at a level of Morphological Structure. It is an interesting question whether the morphological facts presented below can be accounted for under a head-movement analysis recast in the Distributed Morphology framework. See also footnote 18 .

${ }^{8}$ This is not made explicit in Delsing 1993, however.
} 
because $\mathrm{N}$ has failed to move to $\mathrm{D}$. This assumption is, however, problematic when applied to DPs containing a relative clause. As illustrated in 9 and 10, these allow either prenominal or postnominal definiteness marking. ${ }^{9}$

(9) Den hest der vandt løb-et, er til salg. DEF horse that won race-DEF is for sale 'The horse that won the race is for sale.'

(10) Hest-en, der vandt løb-et, er til salg. horse-DEF that won race-DEF is for sale 'The horse, which won the race, is for sale.'

As indicated in the translations, there is a difference in interpretation: a relative clause with prenominal definiteness marking, as in 9 , is interpreted as restrictive, whereas a relative clause with postnominal definiteness marking, as in 10 , allows a nonrestrictive interpretation. ${ }^{10}$ The grammaticality of 9 is unexpected under the head-raising analysis. Consider the structural representation of the subject DP in 11.

\footnotetext{
${ }^{9}$ Under the rules of Danish punctuation (introduced in 1996 by Dansk Sprognævn) only nonrestrictive relative clauses are preceded by a comma (as in English). Unlike English punctuation, all relative clauses that are not sentence final are followed by a comma.

${ }^{10}$ Some speakers also allow a restrictive interpretation for 10 , whereas all speakers exclude a nonrestrictive interpretation for 9 . We return to these facts in section 4.
} 
(11)

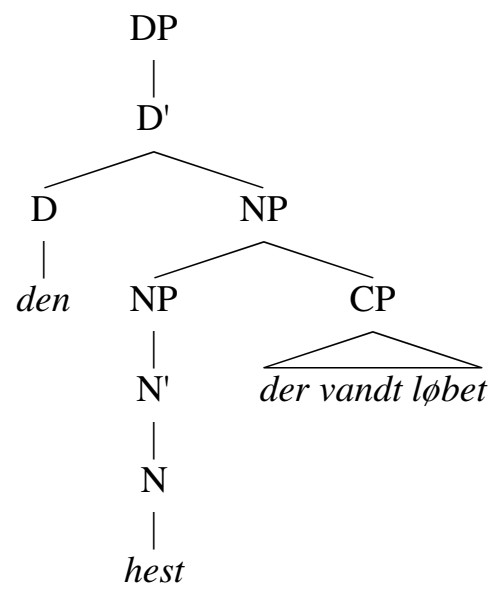

Since N-to-D movement is assumed to be obligatory unless blocked by an intervening head, 9 is predicted to be ungrammatical, or, if den is stressed, to allow only a demonstrative interpretation (compare the discussion of 8 above). However, 9 is grammatical with a stressless den and receives a definite rather than demonstrative interpretation. In 11 we assume that the relative clause is right-adjoined to NP. Our criticism is valid for any structure where the head of the relative clause (C) does not intervene between $\mathrm{D}$ and $\mathrm{N}$. Any structure where the relative clause does intervene between D and N must rely on movement of NP (or of the relative $\mathrm{CP}$ ) to account for the surface order, where relative clauses rigidly follow the noun they modify.

Delsing (1993:119) gives similar data from Swedish and acknowledges that his analysis cannot account for this pattern (see also Börjars 1994:77-78, 194). In section 4 we propose an analysis of relative clauses compatible with the facts in 9 and 10 .

\subsection{Morphological Properties of Definiteness Marking.}

There are at least two instances where definiteness marking is sensitive to morphology. The first involves a morphologically defined class of nouns that do not occur with the postnominal definiteness marker. The second involves proper names that take the definite suffix only when morphologically marked as common nouns. To our knowledge these facts have not been discussed in the generative literature on Danish, though they are mentioned in some descriptive grammars, including Becker-Christensen and Widell (1995:55-56, 95) and Allan et al. (1995:23-24, 239). Börjars (1994:77-82) discusses similar (but not identical) gaps in the distribution of the definite suffix in Swedish. 


\subsubsection{The First Morphological Gap: *studerenden.}

There is a morphologically defined class of nouns that do not occur with the postnominal definiteness marker. The class includes words like studerende 'student', besøgende 'visitor', døende 'dying person', and rejsende 'traveler'. With these nouns a prenominal article is used in all contexts: ${ }^{11}$

(12) a. en studerende

a student

b. den (stakkels) studerende

DEF (poor) student

'the (poor) student'

(13) a. *studerende-en student-DEF

b. *studerend-en student-DEF

Morphologically, studerende is a present participle form composed of the verb studere 'to study' and the morpheme -ende (Allan et al. 1995:239). Present participle forms can be used attributively, as in 14, where they are considered 'adjectival' (Becker-Christensen and Widell 1995:95).

(14) en synkende skude

a sink-PRP ship

'a sinking ship'

Below we show that some participle forms, including studerende, besøgende, etc., behave like nouns in the syntax. The fact that these nouns do not occur with the definite suffix is a problem for the headmovement analysis - where the lack of postnominal definiteness marking is analyzed as the result of lack of head movement-since it is not clear

${ }^{11}$ It is a general property of Danish morphophonology that two adjacent schwas written ee reduce to one (Basbøll 1998:45). The definite form of a noun ending in schwa is realized with a single schwa as illustrated in $\mathrm{i}$.

(i) /mo:lə/ + /ən/ $\rightarrow$ /mo:lən/

pier + DEF

'the pier'

The two starred forms in 13 indicate that both the reduced and the unreduced definite form of studerende are impossible. 
how the internal morphological composition of a noun can prevent the noun from undergoing head movement. Under the Strong Lexicalist Hypothesis (see references cited in footnote 7 above) syntactic operations, such as movement operations, cannot operate on or be sensitive to the internal structure of words. In morphology, on the other hand, gaps and irregularities are ubiquitous, and we take the impossibility of the forms in 13 to be a morphological fact.

There is one complicating factor we need to take into account when arguing that studerende is an $\mathrm{N}$ : Danish allows N-drop under recoverability. ${ }^{12}$ When the descriptive content of $\mathrm{N}$ is recoverable, either from the preceding discourse (15) or from the physical context (16), the $\mathrm{N}$ can be dropped. ${ }^{13}$

(15) A: Hvilken trøje kan du bedst li'? which sweater can you best like 'Which sweater do you like the best?'

B: Den gule.

the yellow

'The yellow one.'

(16) [In a context where the speaker is presented with a set of objects of different colors]

Jeg vil gerne ha' en gul.

I will willingly have a yellow

'I would like to have a yellow one.'

We assume that the elliptical DPs have the following structure, where AP is left-adjoined to an NP with a phonologically null head (notated as ' $\varnothing$ ' in the tree):

\footnotetext{
${ }^{12}$ We use "N-drop" as a descriptive term. In theoretical terms "NP-drop" would be a more adequate term.

${ }^{13}$ The morphological shape of the adjective is sensitive to definiteness (see Mikkelsen 1998b:4-5), hence the different form of the adjective gul 'yellow' in the two examples.
} 
(17)

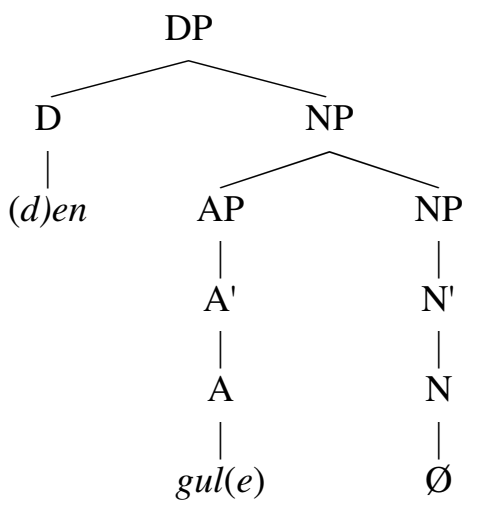

The recoverability condition on $\mathrm{N}$-drop is illustrated in 18: unlike 18a, which contains a non-elliptical DP, $18 \mathrm{~b}$ is deviant without prior mention of people.

(18) a. Jeg kan godt li' skøre folk.

I can well like crazy people

'I like crazy people.'

b. \#Jeg kan godt li' skøre.

I can well like crazy

To justify the claim that studerende is an $\mathrm{N}$, we must rule out the possibility that en studerende 'a student' is an elliptical DP of the structure in 17 , containing only a $\mathrm{D}(e n)$ and an A (studerende). ${ }^{14} \mathrm{We}$ show that this is in fact not the correct analysis, giving two arguments that en studerende 'a student' is not an elliptical DP, and two arguments that studerende is not an adjective, but a noun. These arguments can be carried out for any of the nouns in this class, but we limit the discussion to studerende here. That studerende and the other members of its class are nouns is also acknowledged in Allan et al. 1995:283.

First, en studerende can occur discourse-initially and introduce a discourse referent that may be picked up by a pronoun in the following discourse. In this respect it behaves like a regular indefinite DP, and unlike an elliptical DP:

\footnotetext{
${ }^{14}$ We know from 14 above that present participle forms can be used as attributive adjectives.
} 
(19) [Where a-c are uttered discourse initially]

a. En pige kom gående ned ad gang-en. Hun ... a girl came walking down along hallway-DEF. She ...

b. En studerende kom gående ned ad gang-en. Hun ... a student came walking down along hallway-DEF. She ...

c. *En meget høj kom gående ned ad gang-en. \#Hun ... a very tall came walking down along hallway-DEF. She ... [Intended meaning: 'A very tall person came walking down the hallway.']

Second, in contexts where N-drop is licensed (that is, where the descriptive content of $\mathrm{N}$ is recoverable), it is also possible to have a nonelliptical DP; in other words, N-drop is optional. Moreover, an Ndropped DP is interpreted as if the missing $\mathrm{N}$ were present. Thus 20 and 21 are truth-conditionally equivalent when the missing NP in 20 is understood as bold 'ball', and both are felicitous in a context where this information is recoverable.

(20) Jeg vil gerne ha' den grønne.

I will willingly have DEF green

'I would like to have the green one.'

(21) Jeg vil gerne ha' den grønne bold. I will willingly have DEF green ball 'I would like to have the green ball.'

In contrast, 22 and 23 are not truth-conditionally equivalent, and 23 is in fact marginal.

(22) Jeg så en studerende på gang-en.

I saw a student in hallway-DEF

(23) ? Jeg så en studerende person på gang-en.

I saw a studying person in hallway-DEF

22 can be true in a situation where the person denoted by en studerende is not actually studying in the hallway at the point in time when the speaker sees him or her, as long as that person is a student. In contrast, 23 would be false in this situation. 
Third, studerende cannot take adverbial modifiers like ivrigt 'eagerly', while other present participle forms in attributive position can. ${ }^{15}$

(24) * den ivrigt studerende DEF eagerly student

(25) den ivrigt læsende befolkning

DEF eagerly reading population

In this respect studerende patterns with nouns, which also do not occur with adverbial modification:

(26) * det ivrigt postbud DEF eagerly postman

Fourth, like nouns, studerende can be modified by adjectives, whereas adjectives such as stabil 'reliable' in 28 cannot be modified by another adjective:

(27) Susi og Leo er (dygtige) studerende / postbude.

Susi and Leo are (good) students / postmen

(28) Susi og Leo er (*dygtige) stabile.

Susi and Leo are (good) reliable

Note that in 27 dygtig 'good' is interpreted relative to studerende, that is, as 'good at being students'. Similarly, dygtig is interpreted relative to the noun laerer 'teacher' in 29 , that is, as 'good at being a teacher'.

(29) Susi er en dygtig lærer.

Susi is a good teacher

To summarize: we conclude from the data presented above that studerende is a noun, and that its inability to occur with the definite suffix is due to its morphological properties, specifically the fact that it

${ }^{15}$ The construction in 25 is considered high register, but it is still productive, as evidenced by the attested examples in i from DK87-90 (an electronic corpus of modern written Danish documented in Bergenholtz 1992).

(i) a. de ivrigt kunst-invester-ende japanere

the eagerly art-invest-PRP Japanese

b. de ivrigt fotograferende bil-entusiaster

the eagerly photograph-PRP car-enthusiasts 
contains the present participial morpheme -ende. As mentioned above, this is a problem for the head-movement analysis, since it is not clear how the morphology of a noun can prevent the noun from undergoing movement in the syntax. The morphological sensitivity of the postnominal definiteness marker is further illustrated in the next subsection with respect to definiteness marking of proper names.

2.3.2. The Second Morphological Gap: *Mariaen vs. Mariaerne.

In Danish, as in English, proper names can be used as common nouns and appear, for example, with an indefinite determiner, as in 30 , or plural inflection, as in 31 (Thomsen 1997).

(30) Jeg kender en Maria.

I know a Mary

'I know someone called Mary.'

(31) Jeg kender to Maria-er.

I know two Mary-PL

'I know two people called Mary.'

Proper names can also occur with a prenominal definite determiner in the context of a restrictive relative clause:

(32) Den Maria som jeg kender, bor i København.

the Mary that I know lives in Copenhagen

'The Mary that I know lives in Copenhagen.'

In section 2.2 we showed that postnominal definiteness marking is possible in DPs containing a nonrestrictive relative clause, so we expect these proper names functioning as common nouns to be able to occur with the postnominal article in exactly this context. This expectation is not borne out, as shown by the ungrammaticality of $33 .{ }^{16}$

(33) * Maria-en, som har boet i København i mange år, Mary-DEF who has lived in Copenhagen for many years flyttede til Malmö i januar. moved to Malmö in January

\footnotetext{
${ }^{16}$ The grammaticality of 31 , in particular the wellformedness of the plural form Mariaer, shows that there is nothing phonologically amiss with the sequence -iae-, so this phonological property cannot be the source of the badness of the singular definite form *Mariaen in 33 .
} 
However, when a proper name is marked by plural morphology postnominal definiteness marking is possible with a nonrestrictive interpretation of the relative clause: ${ }^{17}$

(34) Begge Maria-er-ne, som har boet i København i

both Mary-PL-DEF who have lived in Copenhagen for

mange år, flyttede til Malmö i januar.

many years, moved to Malmö in January

'Both the Marys, who have lived in Copenhagen for many years moved to Malmö in January.'

This is thus another instance where the distribution of the definite suffix is sensitive to morphology: only when a proper name form contains overt number morphology can it occur with the definite suffix. The grammaticality of 32 shows that a proper name can function as a common noun without any overt morphological marking. The ungrammaticality of 33 thus cannot be due to Maria not being a noun. To account for these facts under the head-movement analysis, one would have to find a way to rule out head movement of the singular noun Maria in 33, while allowing it for the plural noun in 34. Since the two sentences differ only in morphological and lexical content and not in syntactic structure, this seems highly implausible. ${ }^{18}$

\footnotetext{
${ }^{17}$ In the plural the phonological shape of the definite suffix is invariably -ne.

${ }^{18}$ It should be noted that our contention that the morphologically conditioned gaps provide an argument against the head-movement analysis depends on the assumption that syntactic movements are not subject to essentially morphological constraints. In a theory assuming late lexical insertion, such as that of Distributed Morphology (Halle and Marantz 1993), it is conceivable that the restrictions observed here could be formulated as conditions on complex surface words, such conditions serving as filters on the result of head movement. Under such an approach, head movement could apply freely, and the ill-formed morphological combinations filtered out after the fact. We cannot offer arguments against this line of approach; in fact it is difficult to imagine how there could be arguments against it, other than that nothing so fancy seems to be needed. We content ourselves here with pointing out that the restrictions are clearly morphological restrictions, and a proponent of a head-movement analysis must either impose morphological restrictions on head movement itself or adopt a Distributed Morphology approach, moving at least some of the morphology to a post-syntactic stage. Such well-formed word filters could be grafted on, for example, to the analysis proposed in Embick and Noyer 2001. These moves will
} 
This concludes our discussion of the head-movement analysis. We hope to have shown enough problems with this analysis to justify exploring a different approach to definiteness marking in Danish DPs. In the next section we propose an alternative analysis where definite forms like hesten 'the horse' are in fact determiners derived in the lexicon by a morphological rule. We further reject Delsing's idiosyncratic DP structure and posit a more conservative DP structure, where NP is the complement of D and APs left-adjoin to NP. Our analysis accounts for the distribution of the two definiteness markers without any appeal to movement.

\section{A Morphological Account of Definite Nouns.}

Our central claim is that definite forms like hesten 'the horse' are derived by a morphological rule that combines a noun with the definite suffix to yield a determiner. ${ }^{19}$ The syntactic distribution of these definite forms follows from their status as determiners, while the morphologically defined gaps presented above are analyzed as instances of the morphological rule failing to apply in specific morphologically defined contexts.

Our analysis shares some elements with the Categorial Grammar analysis in Hoeksema 1985:29-30, and the Optimality Theory analysis in Börjars and Donohue 2000:330-348. We discuss these in section 3.4. From the discussion in Börjars 1994:251, it appears that Svenonius (1992a:156-158) considers and rejects (or at least does not pursue) an analysis along the lines that we propose here.

not, however, overcome the theoretical objections to the head-movement analysis raised in section 2.1 , nor will they provide an account of the facts of definiteness marking in relative clause constructions presented in section 2.2.

${ }^{19}$ There is ample evidence that the postnominal definiteness marker is an ordinary suffix, and not, for example, a clitic. Of the six criteria for affix- vs. clitichood given in Zwicky and Pullum 1983, -en comes out as an affix on five (selectivity, irregularity, morphological idiosyncrasies, semantic idiosyncrasies, and participation in syntactic rules), while the sixth criterion (relative linear order) is inconclusive (see Mikkelsen 1998a:57-69 for data and discussion). Börjars (1994:44-83) reaches similar conclusions for the postnominal definiteness marker in Swedish. This result is respected in our analysis, where -en is analyzed as an affix, which combines with an $\mathrm{N}$ stem by a morphological rule in the lexicon. 
The analysis has a morphological component and a syntactic component. In 3.1 we present the morphological rule, Rule D (for Definiteness), and in 3.2 the syntactic structure of Danish DPs. In 3.3 we show how the two combine to account for the distribution of the two definiteness markers.

\subsection{Morphology.}

We assume that a lexical entry for a noun contains at least the following information (where PFORM encodes the phonological shape of the word in question, SREP its semantic representation, GENDER its lexically determined gender, SUBCAT its argument structure, and CAT its syntactic category): ${ }^{20}$

(35) Lexical entry for a noun

$$
\left[\begin{array}{ll}
\text { PFORM } & \alpha \\
\text { SREP } & \beta \\
\text { GENDER } & \gamma \\
\text { NUMBER } & \delta \\
\text { SUBCAT } & \varepsilon \\
\text { CAT } & \mathrm{N} \\
\cdots &
\end{array}\right]
$$

Intuitively, Rule D takes a noun, combines it with the definite suffix and yields a definite determiner. We refer to such determiners as "derived determiners" (they are the things we have up to now been calling definite nouns). Using the lexical representations for nouns introduced above, Rule D can be written as a "Word Formation Rule," in the sense of Aronoff 1976 and Anderson 1992:

\footnotetext{
${ }^{20}$ The lexical representations assumed here could be elaborated in either an HPSG or an LFG framework. We have purposely omitted detail and avoided reference to particular theoretical frameworks, because our analysis only requires that there be lexical representations containing information about the phonological shape, morphological features, morphosyntactic category, and argument structure of the lexical item. We assume that any serious theoretical framework will have to provide this information for lexical items.
} 
(36) Rule D

$\left[\begin{array}{ll}\text { PFORM } & \alpha \\ C A T & \mathrm{~N}\end{array}\right] \Rightarrow\left[\begin{array}{ll}\text { PFORM } & \alpha+\mathrm{EN} \\ C A T & \mathrm{D} \\ D E F & +\end{array}\right]$

Where:

a. EN represents the appropriate form of the definite suffix relative to the number and gender of the noun, ${ }^{21}$

b. DEF is a morphosyntactic feature defined for determiners, but not for nouns (in Danish), introduced by the rule, and assigned the value ' + ', and

c. parts of the entry not mentioned in the rule are not affected.

37 shows how Rule D applies to the noun hest 'horse' to yield the derived determiner hesten 'the horse'. Following Pollard and Sag 1994:19-20, we use <> ('the empty list') as the value of SUBCAT to indicate that hest does not subcategorize for any arguments.

(37) An application of Rule D

$\left[\begin{array}{ll}\text { PFORM } & \text { hest } \\ \text { SREP } & \lambda x \text { horse }(x) \\ \text { GENDER } & \text { common } \\ \text { NUMBER } & \text { sing } \\ \text { SUBCAT } & <> \\ \text { CAT } & \mathrm{N} \\ \cdots & \end{array}\right] \Rightarrow\left[\begin{array}{ll}\text { PFORM } & \text { hesten } \\ \text { SREP } & \lambda x \text { horse }(x) \\ \text { GENDER } & \text { common } \\ \text { NUMBER } & \text { sing } \\ \text { SUBCAT } & <> \\ \text { CAT } & \mathrm{D} \\ \text { DEF } & + \\ \cdots & \end{array}\right]$

In addition to introducing the specification of definiteness, Rule D affects only the values of the PFORM and CAT features. In the remainder of this section we give evidence that the values of all other features remain unchanged.

\footnotetext{
${ }^{21}$ These forms are: -en for common singular nouns, - et for neuter singular nouns, and -ne for plural nouns.
} 
To show that the GENDER and NUMBER values remain unchanged we exploit the fact that predicate adjectives agree in number and gender with the subject DP in a copula clause, as shown in 38 .

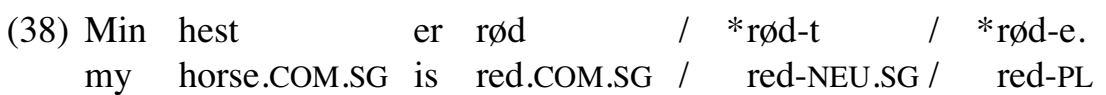

As shown in 39 , agreement is also found when the subject is a derived determiner like hesten, indicating that a derived determiner has the same gender and number features as the nondefinite noun form from which it is derived. ${ }^{22}$

(39) Hest-en

horse-DEF.COM.SG is red.COMSG / red-NEU.SG / red-PL

To see that the SUBCAT value is unaffected by Rule D, consider the data in 40 and 41 .

(40) a. *en hest af ejer-en

a horse of owner-DEF

b. *hest-en af ejer-en

horse-DEF of owner-DEF

(41) a. en ejer af hest-en

an owner of horse-DEF

b. ejer-en af hest-en

owner-DEF of horse-DEF

The noun hest does not allow a PP complement as indicated by the ungrammaticality of $40 \mathrm{a}$. The same is true for the derived determiner hesten in 40b. Contrast this with the examples in 41. Ejer 'owner' is a relational noun subcategorizing for an optional PP complement. The same is true of the derived determiner ejeren 'the owner'. These facts are explained under the assumption that Rule D does not affect the SUBCAT value.

We are not going to present a theory of definiteness here. But we do assume, as virtually everyone does, that determiners are morphosyntactically marked for definiteness and that this marking has ramifications for semantics and/or pragmatics. We offer no speculations as to what Rule D does to the semantic representation (SREP), if anything,

${ }^{22}$ Predicate adjectives do not agree for definiteness. 
or whether definiteness should not be modelled in the semantics at all, but rather in the pragmatic component in relation to discourse factors (such as given vs. new), context, and participants' beliefs (see, for example, Chafe 1976:38-43 and Heim 1988:274-320).

Note that our treatment of definite nouns as determiners can be viewed as an extension of the treatment (first proposed in Postal 1966 and widely accepted since Abney 1987) of personal pronouns as determiners. As with personal pronouns, it is the fact that definite nouns project a DP that accounts for their external syntactic behavior, and it is the definiteness of this DP, inherited from the definite head, that accounts for their semantic/pragmatic behavior.

Rule D, in our conception, may be regarded as a rule extending the lexicon, and as such is "derivational" in a commonly accepted sense of that term. It also effects a category change, which on the commonly accepted view only derivational processes are supposed to be able to do. On the other hand, it adds a morphological feature (DEF) which is relevant to the syntax (in particular to definiteness agreement in Swedish and Norwegian, see section 5), and in that way appears to be "inflectional."

We are not embarrassed by this. It has never been clear that there is a sharp boundary between derivational and inflectional processes, and we in particular do not subscribe to any theoretical persuasion that makes use of such a distinction. It is in any case not clear that the idea that inflectional processes do not change categories would extend to the case of a change from a lexical category to a functional category (one seen on some views as a functional projection of the lexical category in question). What we propose is, in effect, the analogue without movement of the outcome of a head-raising analysis, where a lexical head raises to assume the position (and category) of a functional head. Similarly, Börjars and Donohue suggest that "a definite noun by virtue of the inflection [the definite suffix, JH \& LM] may fill the head position of the nominal functional projection, viz. D." (Börjars and Donohue 2000:344).

In section 2.3 we demonstrated two morphological gaps in the distribution of the definite suffix: it does not occur on nouns ending in -ende (*studerende- $n$ ) and it does not occur on singular proper names (*Maria-en). Regarding the first morphological gap, we do not have anything very interesting to say except that Rule D apparently interacts with other morphological rules, in particular the rules involved in deriving a noun like studerende 'student', in such a way as to produce this gap. Regarding the second gap, we believe that there is a more 
principled morphological explanation for the observed pattern. First we assume that names are lexically of category $\mathrm{D}$ and inherently definite. To account for uses of names as common nouns (Thomsen 1997), we assume there exists a derivational rule converting a name from category $\mathrm{D}$ to category N. A form like *Maria-en could only be derived as a result of Rule D applying to such a derived noun and turning it back into a determiner. The badness of such forms can be viewed as due to a morphological blocking effect: when two forms try to express the same featural content, the morphologically simpler form blocks the more complex form. Since Maria exists as a definite singular determiner, the morphologically more complex form Maria-en, which is featurally indistinct from it, is blocked. Plural definite forms such as Maria-er-ne are not blocked because there is no morphologically simpler form expressing the same content.

Having laid out our assumptions about the morphology of the definiteness marker, we turn to syntax, and the syntactic structure of DP in Danish.

\subsection{Syntax: The Internal Structure of DP.}

A derived determiner like hesten heads a non-branching DP as in 42.

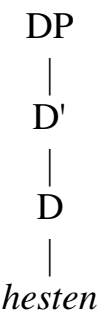

The DP is non-branching because hesten inherits an empty SUBCAT value from hest. Contrast this with the structure for the example in $41 \mathrm{~b}$, where the derived determiner ejeren 'the owner' inherits a non-empty SUBCAT list from the relational noun ejer 'owner', which licenses a PP complement: 
(43)

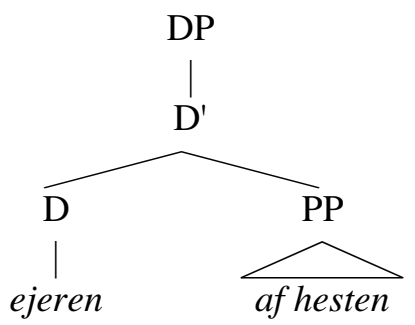

The non-branching DP structure in 42 is exactly like that of personal pronouns like hun 'she', which behaves like a full DP in the syntax and allows no complements.

We take the definite article den to be a transitive determiner taking an NP complement. Contra Delsing 1993, and Abney 1987:327, ex. 381, we assume that NP, never AP, is the complement of D, and that AP, when present, is left-adjoined to NP, as in 44 .

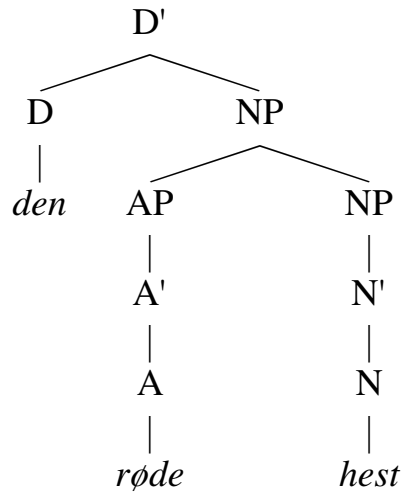

With these syntactic and morphological assumptions in place, we return to the main goal of this paper: accounting for the distribution of the two definiteness markers in Danish.

\subsection{Accounting for the Distributional Facts.}

In this section we account for the following distributional facts:

i. the two definiteness markers are in complementary distribution;

ii. definite forms like hesten 'the horse' do not cooccur with attributive adjectives;

iii. when no attributive adjective is present only postnominal definiteness marking is possible. 
The third fact takes us into an extensive discussion of a blocking effect that is crucial to our analysis. This blocking effect is further motivated in the analysis of relative clauses presented in section 4. It is worth noting that fact three also holds in Norwegian and Swedish, whereas the first two facts do not hold in these languages. In section 5 we suggest how these differences can be accounted for under our approach.

\subsubsection{Complementary Distribution.}

Derived determiners are in complementary distribution with the prenominal definite article:

\section{(45) *den hest-en} the horse-DEF

Under our analysis 45 is ungrammatical because den and hesten are both determiners, and there is only one D position. They cannot both occupy the D position, and neither can take (the other as) a DP complement, compare the structures in 42 and 44 . Similarly, derived determiners cannot co-occur with a possessive form, as shown in 46 .

(46) a. *min hest-en

my horse-DEF

b. *mand-en-s hest-en man-DEF-POSS horse-DEF

c. *Peter-s hest-en Peter-POSS horse-DEF

(47) a. min hest my horse

b. mand-en-s man-DEF-POSS horse

c. Peter-s hest Peter-POSS horse

We suggest that this is because the possessive 's or the possessive pronoun occupies $\mathrm{D}$ and there is no other $\mathrm{D}$ position available for the derived determiner hesten.

3.3.2. No Attributive Adjectives with Postnominal Definiteness Marking. As shown in 48, definite noun forms do not occur with attributive adjectives. 
(48) *røde hest-en

red horse-DEF

The reason 48 is not possible is that there is no NP for the AP to adjoin to in the non-branching DP structure projected by hesten (see the tree in 42). Here the crucial difference between our analysis and the headraising analysis is the absence, under our analysis, of an NP in the syntactic structure of a DP like hesten. This predicts the absence of modifiers that adjoin to NP. A similar explanation is proposed in Börjars and Donohue 2000:344 (see section 3.4).

3.3.3. No Prenominal Definite Article without Modification.

In the absence of modifiers, only postnominal definiteness marking is possible (see the discussion in section 2.2 above).

(49) hest-en

horse-DEF

'the horse'

(50) *den hest

DEF horse

We argue that the impossibility of 50 is due to BLOCKING in the sense of Poser 1992. Poser argues that the well-attested phenomenon of blocking (cf. Paul 1896, Aronoff 1976:43-45), whereby the existence of one form renders an equivalent and otherwise well-formed form ungrammatical, extends to blocking of phrasal forms by lexical ones. In particular, Poser proposes (1992:126) that lexical blocking of phrasal constructions occurs when the phrasal construction instantiates a "morphological category," that is, a category potentially instantiated by a word-formation rule. Essentially, when a word-formation process and a phrase-forming syntactic process compete for the expression of exactly the same morphological category, the word-formation process wins and the phrasal construction is blocked. Poser discusses three instances of such blocking: periphrastic verbs in Japanese, comparative and superlative adjectives in English, and progressive aspect formation in Basque. We suggest that definiteness marking in Danish is another instance, in particular that the existence of the lexical item hesten in 49 blocks the phrase den hest in 50: hesten is derived by a word-formation process (Rule D), blocking the syntactic construction den hest from instantiating the category 'Definite' for the noun hest. A phrase like den røde hest 'the red horse' is not blocked, because there is no corresponding word form 
to block it. Similarly dén hest 'that horse', with the stressed demonstrative dén, is not blocked because it does not mean the same thing as hesten, and the two forms are not competing for expression of the same morphological category. ${ }^{23}$ The assumption of such lexical blocking of phrasal constructions will be crucial to our analysis not only of Danish, but also of Swedish and Norwegian..$^{24,25}$

${ }^{23}$ For a formalization of the blocking principle as applied to definiteness marking in Danish, see Potts 2001:section 2.4.

${ }^{24}$ We will not review here all the literature on lexical blocking of syntactic constructions, but one proposal pre-dating Poser's deserves mention. Postal (1966:188-189) observes the following English facts:

(i) a. I ate the one Schwartz gave me.

(= Postal's 24a)

b. I ate the small one.

(= Postal's 25a)

c. *I ate the one.

$(=$ Postal's 27a)

Postal suggests that the one in i(c) is blocked by the existence of the lexical item it. The blocking effect that Postal is appealing to here seems to be exactly the type of blocking effect discussed by Poser (1992) (though Poser does not refer to Postal's observations) that forms a crucial part of our analysis. We thus take the English facts in i to support the claim that lexical items can block syntactic phrases under synonymy, when the lexical item and syntactic phrase compete for representation of the same morphological category.

${ }^{25}$ Now consider again the morphological wellformedness filter discussed in footnote 18 , as a device for treating the problem of morphological gaps raised in section 2.3 under a head-raising analysis. If such a filter simply applies after obligatory head raising to rule out ill-formed morphological combinations (e.g., *studerenden, *Mariaen) it is not clear why the unraised versions (den studerende, den Maria) should be grammatical. It appears that the only way to avoid making the morphological restrictions conditions on the syntactic movement rule itself is to adopt the blocking condition as part of the analysis. Then head raising could be regarded as optional, the surface morphological wellformedness filter accounting for the morphological gaps, and the blocking condition permitting the phrasal (unmoved) version only when the lexical (headraised) version cannot surface. This revised head-raising analysis, even with the blocking condition, still does not evade the theoretical objections discussed in section 2.1, and still sheds no light on the distribution of definiteness marking in relative clauses. 
3.4. Summary and Comparison with Other Non-movement Analyses.

The analysis proposed here can be summarized as follows:

i. The definite suffix combines directly with an $\mathrm{N}$, yielding a D realizing the morphological feature [+ DEF].

ii. This D projects a DP which inherits the [+ DEF] specification from its head.

iii. The definite article combines with an NP to yield a DP; this DP inherits the $[+\mathrm{DEF}]$ specification from its head, the inherently [+ DEF] article.

iv. APs adjoin to NPs and not to DPs; this accounts for the noncooccurrence of adjectives with the definite suffix.

v. When a DP formed by projection of a definite noun $(\mathrm{N}+\mathrm{EN})$ competes with a DP formed by the syntactic combination of the definite article with an NP to express the same morphosyntactic category, the syntactic combination is blocked and the morphological one wins.

We have presented this analysis as a non-movement alternative to the movement analysis proposed in Delsing 1993. Two other non-movement approaches deserve discussion here: the Categorial Grammar analysis sketched in Hoeksema 1985:29-30 and the Optimality Theory analysis presented in Börjars and Donohue 2000:330-348.

Hoeksema (1985:30) proposes that the definite suffix is a member of the category $\mathrm{N}^{0} \backslash \mathrm{NP}$ : it combines with a preceding noun $\left(\mathrm{N}^{0}\right)$ to form an NP (which corresponds to a DP in our analysis). Adjectives are of category $\mathrm{N}^{\prime} / \mathrm{N}$, where $\mathrm{N}$ is the union of $\mathrm{N}^{0}$ and $\mathrm{N}^{\prime}$. This allows adjectives to combine with nouns $\left(\mathrm{N}^{0} \mathrm{~s}\right)$ as well as adjective-noun combinations (N's), but not with definite nouns, since these are NPs (i.e., in current terms, DPs). Though Hoeksema does not discuss the lack of double definiteness (i.e., a definite noun coocurring with a definite article), this would follow from the definite article being specified as a member of the category NP/N'.

The crucial difference between this proposal and ours is that Hoeksema assumes that the definite suffix combines with a lexical item to form a phrase, where we assume that the definite suffix combines with a lexical item to form another lexical item (a determiner), which, in the syntax, projects a phrase (DP). This difference is significant in the case of nouns that subcategorize for a complement. We assume that a derived determiner inherits the subcategorization of the noun from which it is derived (see examples 40 and 41 in section 3.1). If a noun can take a 
complement, the determiner derived from it can take the same complement. In the syntax, the complement appears as a sister to the head of which it is a complement. The complement of a derived determiner thus appears as a sister to $\mathrm{D}^{0}$. This is unproblematic on our analysis where the derived D projects a DP structure; see the tree in 43. For Hoeksema, however, the definite suffix combines with the noun to form an NP (equivalent to our DP) and there is no appropriate position for a complement, that is, a position where it is the sister of the lexical head that it is a complement of.

Börjars and Donohue (2000) (hereafter B\&D) propose an Optimality Theoretic analysis of feature realization in Germanic noun phrases, concentrating on number, gender, and definiteness marking in Dutch and Danish. For Danish they assume that definiteness (DEF) is a phrasal feature, that is, a feature that is realized only once within a given domain, here the noun phrase (B\&D 318-319). In Danish, definiteness can be realized either syntactically, by the definite article, or morphologically, by the definite suffix. The choice between the two is determined by constraint ranking, in particular the relative ranking of the markedness constraints AVOID-S(YNTAX) and AVOID-M(ORPHOLOGY). AVOID-S punishes syntactic structure and AVOID-M morphological structure. B\&D propose that, in Danish, AVOID-S outranks AVOID-M. This has the effect of ruling out den hest 'the horse' in favor of hesten 'horse-DEF' as the output for an input like 'horse, DEF'. This constraint ranking thus plays a role similar to that played by the blocking principle in our analysis. As B\&D note (p. 338) the ranking of AVOID-S over AVOID-M also predicts, incorrectly, that *store hesten 'big horse-DEF' should rule out den store hest 'the big horse'. They discuss two possible solutions to this problem without deciding in favor of either of them.

The first solution is to assume that a referential noun phrase can be either an NP or a DP as long as it is marked for definiteness, and further that APs attach outside NP, forcing a DP projection (B\&D 344). A general requirement that a projection have a lexically filled head position will then force a lexical determiner to appear in noun phrases with attributive adjectives. Double definiteness marking is ruled out by AVOID-M. To us this solution suffers from the implausibility of the assumption that APs must adjoin outside NP.

Their second solution, which is similar to our account of why definite nouns do not cooccur with adjectives, assumes that all referential noun phrases are DPs and that APs adjoin inside the N-projection. Further, "a definite noun by virtue of the inflection [the definite suffix, 
JH \& LM] may fill the head position of the nominal functional projection, viz. D" (B\&D 344). ${ }^{26}$ This is what explains why a definite noun like hesten can function as an argument without a lexical determiner. Since APs must adjoin within NP, the presence of an adjective forces an NP projection. Like all projections, the NP must have a lexically filled head position. If the definite noun occupies $\mathrm{D}^{0}, \mathrm{~N}^{0}$ is left empty in violation of the constraint against empty heads. By ranking this constraint above AVOID-S the presence of both a lexical determiner and a lexical noun is ensured, favoring den store hest 'the big horse' over *store hesten 'big horse-DEF'. As before, double definiteness (*den store hesten 'the big horse-DEF') is ruled out by AVOID-M.

Though B\&D do not discuss complements, there appears to be nothing in their analysis, unlike in the analysis of Hoeksema (1985), that would prevent definite nouns appearing in $\mathrm{D}^{0}$ from taking complements according to their lexical subcategorization properties. Neither of these analyses addresses the issue of definiteness marking in relative clause constructions. As noted above, definiteness marking in DPs containing a relative clause differs from definiteness marking in DPs without relative clauses. In the next section we provide an analysis of these differences that relies crucially on the notion of blocking.

\section{Relative Clauses.}

In section 2.1 we saw that relative clauses cooccur with either a prenominal definite article or a definite suffix (though never with both), and pointed out that the cooccurence with the prenominal article in the absence of prenominal modifiers is problematic for the head-raising analysis, as it is implausible that there is any intervening head to block $\mathrm{N}$ raising to $\mathrm{D}$ on any analysis of relative clause structures. Thus under the head-raising analysis, we would expect to find the same distribution of the definite markers as in simpler constructions, that is, the suffixed form if no prenominal adjectives are present, and the prenominal article otherwise.

When one or more prenominal adjectives are present, the suffixed form is indeed impossible; but when there are no prenominal adjectives, both 52 and 53 (repeated from 9 and 10 above) are grammatical:

\footnotetext{
${ }^{26}$ This aspect of the B\&D analysis is thus very close in spirit to our own; our proposal, at the cost of stating a rule, has the virtue that it is explicit about exactly how the definite nouns come to behave as determiners.
} 
(52) den hest der vandt løb-et DEF horse that won race-DEF 'the horse that won the race'

[all speakers]

(53) hest-en der vandt løb-et horse-DEF that won race-DEF 'the horse, which won the race' [all speakers] 'the horse that won the race' [some speakers]

As noted above, the interpretations are somewhat complicated, but important. In 52, the only possible interpretation of the relative clause is as a restrictive one; in 53, for some speakers the only possible interpretation is nonrestrictive, while for others a restrictive interpretation is also possible (Mikkelsen 1998a:39-42). This may be an instance of language change in progress, since it is mostly oldergeneration speakers for whom 53 is exclusively interpreted as nonrestrictive.

We do not understand the variation or change involved in 53. We do, however, believe that we understand the reason why 52 can only be interpreted as restrictive. We assume that there are two places where a relative clause can adjoin: to NP, as in 55 (repeated from 11 above); or to DP (or higher), as in $56:^{27,28}$

${ }^{27}$ It does not matter exactly where nonrestrictive relative clauses attach, as long as it is at the level of DP or higher, that is, as long as they are not attached inside DP, while relative clauses attached to NP, that is, inside DP, are unambigiously restrictive. See McCawley 1988:420-428 for representative discussion of the structural differences between restrictive and nonrestrictive relative clauses.

${ }^{28}$ Note that restrictive relative clauses are also possible with personal pronouns, which we assume are also Ds:

(i) Jeg kender ham der vandt løb-et.

I know him who won race-DEF

'I know the guy who won the race.'

This shows that restrictive relative clauses can, at least in some contexts, be adjoined to DP. 
(55)

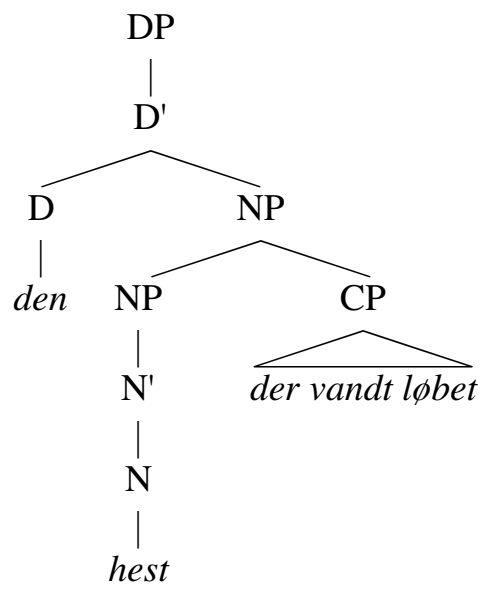

(56)

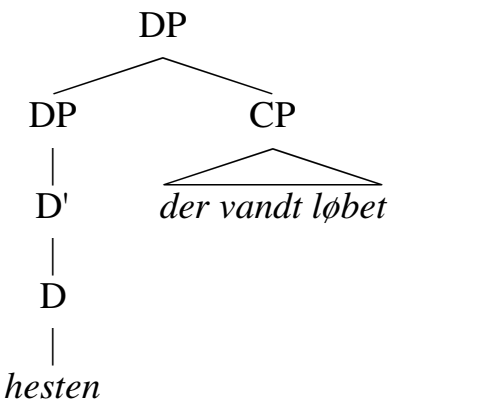

We propose that, in order to get the nonrestrictive interpretation, the relative clause must be adjoined to DP (or higher), as in 56. A relative clause attached to NP, as in 55, has only a restrictive interpretation.

Under these assumptions, we can see straightforwardly why there is a gap in the interpretation possibilities for 52. To get a nonrestrictive interpretation with that order of words, the structure would have to be as in 57 : 


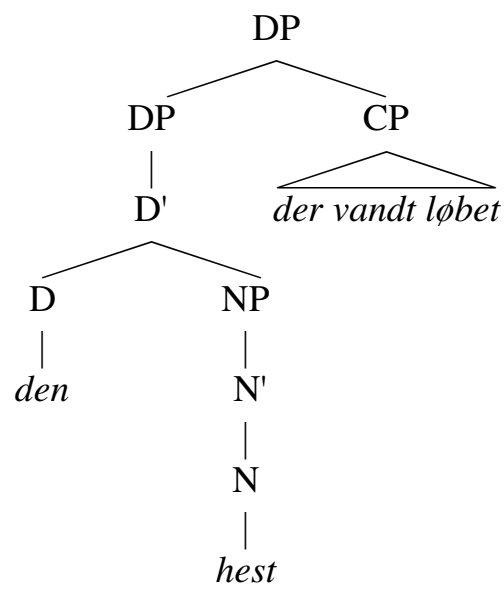

But this structure contains the DP den hest, which is blocked by the existence of hesten. Thus there is no way for 52 to have a nonrestrictive interpretation. The reason that the restrictive relative clause construction in 55 is not blocked is that in this structure den hest does not form a phrase and only phrases can be blocked by lexical items.

\section{Swedish and Norwegian.}

Now that we have developed and justified an analysis of definiteness marking in Danish based on a morphological rule of definitization (Rule D), it is reasonable to ask how this analysis would extend to the other Mainland Scandinavian languages, Swedish and Norwegian. We will not deal here with Icelandic and Faroese, because we have not had the opportunity to investigate the phenomenon in those languages in any depth. $^{29}$

In Swedish and Norwegian, the basic pattern is similar to Danish in nominal expressions lacking a prenominal modifier, as illustrated by the Swedish examples below from Börjars 1994:17, 217: ${ }^{30}$

(58) mus-en

mouse-DEF

\footnotetext{
${ }^{29}$ We further concentrate on the standard languages of Mainland Scandinavian. Some dialectal differences are discussed in Delsing 1993:122-123.

${ }^{30}$ As in Danish, there is a stressed version of the definite article that functions as a demonstrative. If den is stressed, 60 is possible with a demonstrative interpretation (that mouse) (Börjars 1994:217).
} 


$$
\begin{gathered}
\text { (59) } * \text { den mus } \\
\text { DEF mouse } \\
\text { (60) } * \text { den mus-en } \\
\text { DEF mouse-DEF }
\end{gathered}
$$

But when a prenominal adjective is present, both the article and the definite suffix appear (Börjars 1994:241):

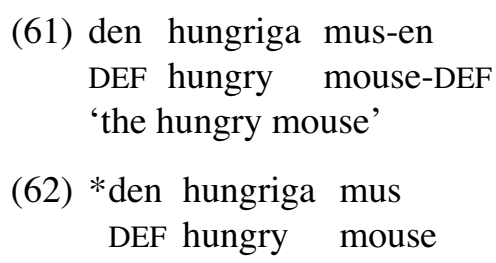

The double marking of definiteness in 61 has drawn the attention of a number of linguists, including Börjars (1994, 1995), Börjars and Donohue (2000), Payne and Börjars (1994), Delsing (1988, 1993), Santelmann (1993), Svenonius (1993), and Taraldsen (1991). Our proposed account of this pattern is that in Swedish and Norwegian, a definite noun like musen 'the mouse' is ambiguously either a $\mathrm{D}$, as in Danish, or an $\mathrm{N}$, where the definite suffix marks the $\mathrm{N}$ morphologically as definite, serving in this case as a kind of agreement feature as suggested in Börjars and Donohue (2000:331). ${ }^{31}$ A simple way of implementing this conception would be to say that Swedish and Norwegian have the definitization rule (Rule D) of Danish, but in these languages the category change $(\mathrm{N} \rightarrow \mathrm{D})$ part of the rule is optional. We will then assume that in Swedish and Norwegian the definite article subcategorizes for a morphologically definite NP complement (see Svenonius 1993 for a similar analysis).

From these assumptions, the patterns of definiteness marking in Swedish and Norwegian follow straightforwardly. A definite noun, such as that in 58, can serve as a DP because the lexicon provides a D of that form (by Rule D). The ungrammaticality of 59 follows, as in Danish, from the blocking effect. The ungrammaticality of 60 also follows from

\footnotetext{
${ }^{31}$ Delsing assumes that "Swedish and Norwegian may have the suffixed article base generated on the noun in N" (1993:129). When head movement of the noun to $\mathrm{D}$ is blocked by an intervening adjective, the $\mathrm{D}$ position is filled by an expletive article, resulting in double definiteness marking (Delsing 1993:130-131).
} 
the blocking effect; such a construction was not even considered in Danish because Danish does not have any definite nouns that are nouns syntactically. This analysis of 60 also explains why the string in 60 is possible with a demonstrative interpretation (cf. footnote 30): blocking only happens under synonymy, and there is no lexical synonym to the demonstrative phrase dén musen 'that mouse'.

Example 61 is grammatical, contrary to the parallel case in Danish, because Swedish and Norwegian have Ns that are morphologically definite; 62 is ungrammatical because in Swedish and Norwegian definite articles like den select the morphologically definite form of the N heading their complement, precisely as proposed in Börjars 1994:273, Svenonius 1993:204, and Embick and Noyer 2001:583.

Given these assumptions, we are forced to make some predictions concerning relative clauses in Swedish and Norwegian. We must assume that the same two adjunction possibilities are available, that is, CP adjoined to DP (or higher) or to NP; and that only the higher adjunction will yield a nonrestrictive interpretation. Then, just as in Danish, we predict that 63 can only have a restrictive interpretation, while 64 may be interpreted nonrestrictively (data from Börjars 1994:77-78, 194):

(63) a. Den mus-en som vi såg hade inte ätit ost-en. DEF mouse-DEF which we saw had not eaten cheese-DEF

b.

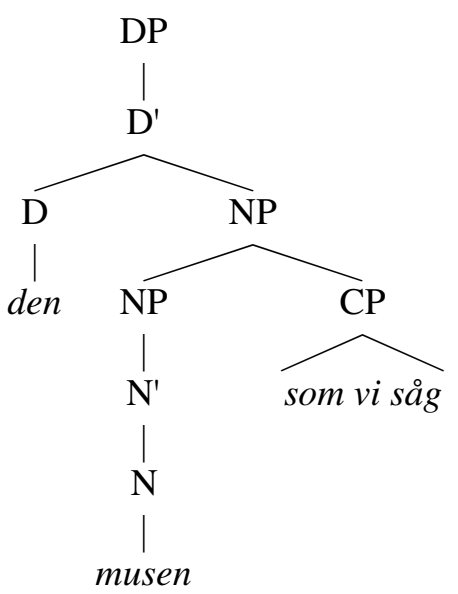

(64) a. Mus-en som vi såg hade inte ätit ost-en. mouse-DEF which we saw had not eaten cheese-DEF 
b.

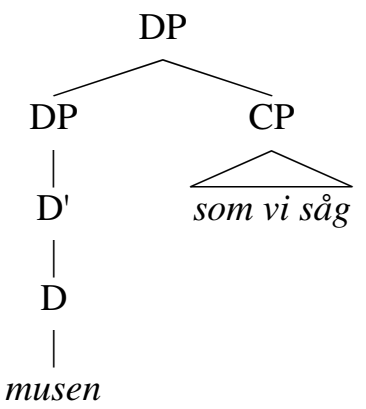

The reason is that, just as in Danish, Swedish and Norwegian have a derived $\mathrm{D}$ (musen), the existence of which blocks the phrasal form den musen, depriving $63 \mathrm{a}$ of a structure similar to $64 \mathrm{~b}$. Indeed, the relative clause interpretation possibilities in Swedish and Norwegian appear to be exactly the same as in Danish. In particular, 63a has only a restrictive interpretation when den is pronounced and interpreted as a definite article. When den is stressed and interpreted as a demonstrative a nonrestrictive interpretation is possible (Kersti Börjars p.c. July 2, 2001). ${ }^{32}$

\section{Conclusion.}

We have argued that the morphosyntax of definiteness marking in Danish (and in other Mainland Scandinavian languages) is best accounted for not by an analysis involving head raising, but by a wordformation rule which marks a noun as definite and simultaneously changes its category to D. This move may seem dismaying, in that we suggest that what was thought to be a closed category (even a "functional" one) is in these languages expanded by a morphological rule to an open category. This move, however, allows us to maintain an otherwise very conservative set of assumptions about the syntax of these constructions, and, together with the assumption of lexical blocking of

${ }^{32}$ Note that $\mathrm{i}$ is also possible in Swedish (data from Börjars 1994:194).

(i) Den mus som vi såg hade inte ätit ost-en. DEF mouse which we saw had not eaten cheese-DEF

We assume that $\mathrm{i}$ has the structure of $63 \mathrm{~b}$. Otherwise den mus would be blocked. We thus predict that the relative clause in i can be only restrictive. This is confirmed by Börjars (1994) in the discussion of her example 3.22b, page 77 . The surprising fact about $\mathrm{i}$ is that the definite form of the $\mathrm{N}$ is not required. We have found no solution to this puzzle in the literature. 
phrasal constructions, to account straightforwardly for the central facts of definiteness marking in the Mainland Scandinavian languages as well as some previously unexplained phenomena concerning relative clauses.

Two directions suggest themselves for further investigation. On the one hand, there are other cases where a tight relationship of some kind exists between a determiner and an immediately following noun, expressed in a morphological and/or phonological reflex, which is blocked by the presence of an intervening adjective.

Leu (2001) discusses a phenomenon in Swiss German, where the definite article takes a reduced, phonologically assimilated form when immediately followed by a noun, but invariably the full, independent form $d i$ when an adjective intervenes (similar facts are mentioned in Hoeksema 1985:29-30):

(65)
d autobahn the highway (fem)
b. $*$ d / di alt autobahn the old highway

(66) a. $\mathrm{k}$ xint the children (plural)
b. *k/di xlinä xint the little children

$$
\begin{aligned}
& (=\text { Leu's 1a) } \\
& (=\text { Leu's 1b) } \\
& (=\text { Leu's 2a) } \\
& \text { (= Leu's 2b) }
\end{aligned}
$$

This and similar determiner-adjective-noun interactions in other languages might be worth exploring from the perspective applied to definiteness marking in Danish above.

The second direction for exploration is somewhat broader. If we have succeeded in arguing that a head-raising analysis is unsuccessful in accounting for the problem of definiteness marking in Danish, and if in turn the alternative approach to this morphosyntactic problem that we develop here is accepted as promising, then it might be fruitful to reconsider other analyses involving head raising as a crucial mechanism in accounting for some interactions between morphology and syntax.

\section{REFERENCES}

Abney, Steven. 1987. The English noun phrase in its sentential aspect. Doctoral dissertation, MIT.

Allan, Robin, Philip Holmes, and Tom Lundskær Nielsen. 1995. Danish: A comprehensive grammar. London: Routledge. 
Anderson, Stephen R. 1992. A-morphous morphology. Cambridge: Cambridge University Press.

Aronoff, Mark. 1976. Word formation in generative grammar. Cambridge, MA: MIT Press.

Basbø1l, Hans. 1998. Nyt om stødet i moderne rigsdansk—om samspillet mellem lydstruktur, ordgrammatik og kognitive principper. Pluradicta 35:1-61. (Working papers series published by the Institute of Language and Communication, Odense University.)

Becker-Christensen, Christian, and Peter Widell. 1995. Politikens nudansk grammatik. København: Politiken.

Bergenholtz, Henning. 1992. Dansk frekvensordbog: baseret på danske romaner, ugeblade og aviser, 1987-1990. København: G. E. C. Gad.

Börjars, Kersti. 1994. Feature distribution in Swedish noun phrases. Doctoral dissertation, University of Manchester. (Published 1998. Oxford: Blackwell.)

- 1995. Swedish double determination in a European perspective. Nordic Journal of Linguistics 17:219-252.

Börjars, Kersti, and Mark Donohue. 2000. Much ado about nothing: Features and zeroes in Germanic noun phrases. Studia Linguistica 54:309-353.

Chafe, Wallace L. 1976. Givenness, contrastiveness, definiteness, subjects, topics, and point of view. Subject and topic, ed. by Charles N. Li, 25-56. New York: Academic Press.

Delsing, Lars-Olof. 1988. The Scandinavian noun phrase. Working Papers in Scandinavian Syntax 42:57-79.

- 1993. The internal structure of noun phrases in the Scandinavian languages. Doctoral dissertation, University of Lund.

Diderichsen, Paul. 1946. Elementær dansk grammatik. København: Nordisk.

Duffield, Nigel. 1995. Particles and projections in Irish syntax. Boston: Kluwer.

Embick, David, and Rolf Noyer. 2001. Movement operations after syntax. Linguistic Inquiry 32:555-595.

Halle, Morris, and Alec Marantz. 1993. Distributed Morphology and the pieces of inflection. The view from Building 20 : Essays in linguistics in honor of Sylvain Bromberger, ed. by Kenneth Hale and Samuel Jay Keyser, 111-175. Cambridge, MA: MIT Press.

Hankamer, Jorge, and Line Hove Mikkelsen. 2001. The morphosyntax of definiteness in Danish. In Mac Bhloscaidh (ed.), 59-81.

Hansen, Aage. 1927. Bestemt og ubestemt substantiv. København: Arnold Busck.

Heim, Irene. 1988. The semantics of definite and indefinite noun phrases. New York: Garland.

Hoeksema, Jack. 1985. Categorial morphology. New York: Garland.

LaPointe, Steven G. 1980. A lexical analysis of the English auxiliary verb system. Lexical grammar, ed. by Teun Hoekstra, Harry van der Hulst, and Michael Moortgat, 215-254. Dordrecht: Foris. 
Leu, Thomas. 2001. A sketchy note on the article-modifier relation. Generative Grammar in Geneva 2:55-69.

Longobardi, Giuseppe. 1994. Reference and proper names. Linguistic Inquiry 25:609-665.

Mac Bhloscaidh, Séamus (ed.). 2001. Syntax and semantics at Santa Cruz. Vol. 3. Santa Cruz: Slug Publications.

McCawley, James D. 1988. The syntactic phenomena of English. Vol. 2. Chicago: University of Chicago Press.

Mikkelsen, Line Hove. 1998a. Definiteness marking in Danish: A corpus-based study of the distribution of the pre- and postnominal definite articles. Master's thesis, Aarhus Universitet, Denmark.

. 1998b. An HPSG analysis of agreement in Danish noun phrases. (Technical Report EUCCS-RP-1998-5.) Edinburgh: Centre for Cognitive Science, University of Edinburgh.

Mohammad, M. A. 1988. On the parallelism between IP and DP. Proceedings of West Coast Conference on Formal Linguistics (WCCFL) 7, ed. by Hagit Borer, 241-254. Stanford, CA: CSLI.

Paul, Hermann. 1896. Über die Aufgaben der Wortbildungslehre. Sitzungsberichte der philosophisch-philologischen und der historischen Classe der Königlich Bayerischen Akademie der Wissenschaften zu München, Jahrgang 1895, 692-713. Munich: Verlag der K. Akademie.

Payne, John, and Kersti Börjars. 1994. Swedish noun phrases meet Categorial Grammar. Proceedings of the special session on Scandinavian syntax at the VIIIth Conference of Nordic and General Linguistics, 111-126. (Gothenburg papers in theoretical linguistics, 70.) Gothenburg: University of Gothenburg.

Pollard, Carl, and Ivan A. Sag. 1994. Head-Driven Phrase Structure Grammar. Chicago: University of Chicago Press.

Poser, William J. 1992. Blocking of phrasal constructions by lexical items. Lexical matters, ed. by Ivan A. Sag and Anna Szabolcsi, 111-130. Stanford, CA: CSLI.

Postal, Paul. 1966. On so-called "pronouns" in English. Problems in semantics, history of linguistics, linguistics and English, ed. by Frances P. Dinneen, 177-206. (Georgetown monograph series on languages and linguistics, 19.) Washington, DC: Institute of Languages and Linguistics, Georgetown University.

Potts, Christopher. 2001. Three kinds of transderivational constraint. In Mac Bhloscaidh (ed.), 21-40.

Pullum, Geoffrey, and Arnold Zwicky. 1991. A misconceived approach to morphology. Proceedings of West Coast Conference on Formal Linguistics (WCCFL) 10, ed. by Dawn Bates, 387-398. Stanford, CA: Stanford Linguistics Association.

Ritter, Elizabeth. 1988. A head-movement approach to construct-state noun phrases. Linguistics 26:909-929. 
Rizzi, Luigi. 1990. Relativized minimality. Cambridge, MA: MIT Press.

Santelmann, Lynn. 1993. The distribution of double determiners in Swedish. Studia Linguistica 47:154-176.

Scalise, Sergio. 1984. Generative morphology. Dordrecht: Foris.

Svenonius, Peter. 1992a. The distribution of definite marking. Papers from the workshop on the Scandinavian noun phrase, ed. by Anders Holmberg,

135-164. (DGL-UUM report 32.) Umeå: Department of General Linguistics, University of Umeå.

- 1992b. The extended projection of N: Identifying the head of the noun phrase. Working Papers in Scandinavian Syntax 49:95-121.

1993. Selection, adjunction, and concord in the DP. Studia Linguistica 47:198-220.

Taraldsen, Knut Tarald. 1991. Two arguments for functional heads. Lingua 84:85-108.

Thomsen, Hanne Erdman. 1997. On the proper treatment of proper names. Nordic Journal of Linguistics 20:91-110.

Travis, Lisa. 1984. Parameters and effects of word order variation. Doctoral dissertation, MIT.

Zwicky, Arnold M. 1985. Heads. Journal of Linguistics 21:1-29.

Zwicky, Arnold M., and Geoffrey K. Pullum. 1983. Cliticization vs. inflection: English $n$ 't. Language 59:502-513.

Department of Linguistics

University of California, Santa Cruz

1156 High Street

Santa Cruz, CA 95064

[hank@ling.ucsc.edu]

[mikkelsen@ling.ucsc.edu] 